\title{
Analytical Method Development and Validation of Phenothrin, Promecarb and Penconazole in Tobacco using Liquid Extraction and Gas Chromatography
}

\author{
Hale Seçilmiş Canbay* \\ Department of Bioengineering, Faculty of Engineering and Architecture, Burdur Mehmet Akif Ersoy University, \\ 15030 Burdur, Turkey. \\ *halecanbay@mehmetakif.edu.tr
}

Received: 23 July 2018

Accepted: 25 September 2018

DOI: $10.18466 /$ cbayarfbe. 446820

\begin{abstract}
A sensitive method for the determination of phenothrin, promecarb and penconazole residues in tobacco has been developed. Several solvents such as, hexane, ethyl acetate and dichloromethane were tested in order to minimize agricultural products residue. In the study, the best recovery was achieved with dichloromethane. Pesticides residues are extracted from the samples with dichloromethane. Additional clean-up steps are not required for tobacco matrices. Determination and quantification of phenothrin, promecarb and penconazole are performed by gas chromatography-flame ionization detector (GC/FID) and gas chromatography-nitrogen/phosphorus (GC/NPD). The method has been validated for tobacco matrices. Under the optimum conditions, phenothrin $\mathrm{R}^{2}$ value 0.999 , promecarb $\mathrm{R}^{2}$ value 0.999 , and penconazole $\mathrm{R}^{2}$ value 0.999 . Limits of determination were $0.008 \mu \mathrm{g} \mathrm{mL}^{-1}$ for phenothrin, $0.011 \mu \mathrm{g} \mathrm{mL}^{-1}$ for penconazole and $0.007 \mu \mathrm{g} \mathrm{mL}^{-1}$ for promecarb. The standard deviations (SDs) levels were in the range 0.01-0.20. Recoveries of phenothrin, promecarb and penconazole from tobacco were found to be higher than $85 \%$. Under this developed method, the concentrations of phenothrin, promecarb and penconazole in the 10 tobacco samples were below the LOD values.
\end{abstract}

Keywords: Tobacco, GC, phenothrin, promecarb, penconazol, liquid extraction.

\section{Introduction}

Every chemical substance points out in the environmental desirable and undesirable effect. Public has exposed to a mixture of different chemical substance (pesticides, insect repellents, polychlorinated biphenyls, phthalates, paints, glues, etc.) in food, water and related commodities has been increasing during the past 20-30 years. In recent years, the use of pesticides has been increased to quality and quantity of agricultural and daily chemical products $[1,2]$. Pesticides contain potential risk to both human and natural life [3, 4].

Penconazole is widely used to control powdery mildew in apple, squash, pear, redcurrants grape, and blackcurrants and some ornamental plants and vegetable [5]. Phenothrin is widely used in mosquito control programs to kill adult mosquitoes. Promecarb pesticide kills insects.

Numerous analytical methods for determining penconazole, promecarb and phenothrin residues in various matrix have been published. Analyses of pesticides have been based on chromatographic and spectroscopic methods 6-20]. Before penconazole, promecarb and phenothrin residues were determined, samples required sample preaperation part (extraction and purification) [6-20].

The mass spectrometers used in the studies are expensive techniques. The aim of the study is to develop a method for the analysis of penconazole, promecarb and phenothrin with the cheaper technique GC FID/NPD.

\section{Materials and Methods}

\subsection{Apparatus}

Apparatus GC was Agilent 7890A gas chromatograph equipped with a flame ionization detector (FID) and nitrogen-phosphorus (GC/NPD) detector, a 7693B automatic sampler and a GC data system.

An ultrasonic bath (Bandelin Sonorex, Germany) was used for extraction. A rotary evaporator (Heidolph, Germany) was used for concentrating.

\subsection{Instrumental Conditions}

Gas Chromatograph equipped with a DB-5MS (5\% diphenyl/95\% dimethyl poly siloxane) fused a capillary column $(30 \times 0.25 \mu \mathrm{m} \mathrm{ID} \times 0.25 \mu \mathrm{m} \mathrm{df})$. Helium gas $(99.999 \%)$ was used as a carrier gas at a constant flow 
rate of $20 \mathrm{psi}$, and an injection volume of $1 \mu \mathrm{l}$ was employed. The injector temperature was maintained at $300{ }^{\circ} \mathrm{C}$, detector temperature was $300^{\circ} \mathrm{C}$, the oven temperature was programmed from $80^{\circ} \mathrm{C}$ (isothermal for $1 \mathrm{~min})$, with an increase of $10^{\circ} \mathrm{C} \mathrm{min}^{-1}$ to $160^{\circ} \mathrm{C}$ (isothermal for $5 \mathrm{~min}$ ), then $3^{\circ} \mathrm{C} \mathrm{min}^{-1}$ to $280^{\circ} \mathrm{C}$.

\subsection{Chemicals and Reagents}

Hexane (HPLC grade), dichloromethane (HPLC grade), toluene (HPLC grade), ethyl acetate (analytical-reagent grade), phenothrin, penconazole and promecarb were obtained from Merck (Dermstadt, Germany), Dr. Ehrenstorfer (Augsburg, Germany) and Sigma-Aldrich (Dermstadt, Germany), respectively.

\subsection{Extraction Producedure of Pesticides from the Tobacco}

Approximately $250 \mathrm{~g}$ of the tobacco sample was sliced by knife and mixed for $10 \mathrm{~min}$ in the blender. Fifteen grams of homogenised sample were weighed in a 400 $\mathrm{ml}$ beaker and extracted and ultrasonicated for $25 \mathrm{~min}$ with $125 \mathrm{ml}$ extraction solvent. Extract was filtered with Whatman filter paper. After filtration through filter paper, the residue was re-extracted with $125 \mathrm{ml}$ extraction solvent. The eluate fraction was concentrated using the rotary vacuum evaporator (water bath $40^{\circ} \mathrm{C}$ ), and solvents were removed by under a gentle nitrogen stream. The residue was resolved in $1 \mathrm{ml}$ toluene, transferred into a GC autosampler vial.

\subsection{Analytical Method Validation and Performance Criteria}

The analytical method was tested to evaluate different validation parameters: linearity, specificity, precision, limit of detection (LOD) and accuracy. Calibration curves are plotted to obtain six different calibration levels to find the linearity of the system. To determine the LOD value, the $\mathrm{S} / \mathrm{N}$ ratio was used as 3: 1. The inter-day and intra-day precision of the tested analytical method was represented as standard deviation ratio (SD) of within-laboratory reproducibility target pesticides analysis at 5 different days. The accuracy of the method was expressed in terms of average recoveries of spiked blank sample with each compound in three replicates. All standards and calibration solutions were prepared in toluene.

\section{Results and Discussion \\ 3.1 Method validation}

Linearity: The calibration curves were established with six different concentrations (Table 1). In analytical studies, linearity of the method is expressed in terms of the results (area, height, and absorbance) that vary linearly with the analyte concentration in a given working range. In order to determine the linearity of the tested method, the least square method is used in the calculation of the numerical data mathematically. It is expressed by the regression coefficient value.

Precision: Precision may be a measure of either the degree of repeatability/reproducibility of the tested analytical method under worked condition. Repeatability was determined using three different concentrations of pesticide prepared and analyzed. Intraday and interday instrument variations were studied to determine the sensitivity of the proposed tested analytical methods (Table 2). The precision of a tested analytical method is usually expressed as the standard deviation (SD) of a series of measurements.

Table 1. Some method validation values of studied pesticides.

\begin{tabular}{|c|c|c|c|}
\hline Parameters & $\begin{array}{c}\text { Obtained values } \\
\text { (phenothrin) }\end{array}$ & $\begin{array}{c}\text { Obtained values } \\
\text { (penconazole) }\end{array}$ & $\begin{array}{c}\text { Obtained values } \\
\text { (promecarb) }\end{array}$ \\
\hline Detector & FID & NPD & NPD \\
\hline Linearity $\left(\mu \mathrm{g} \mathrm{mL}^{-1}\right)$ & $2.50-10.00$ & $0.30-1.50$ & $0.40-2.00$ \\
\hline $\mathrm{R}^{2}($ Regression coefficient value $)$ & 0.999 & 0.999 & 0.999 \\
\hline LOD $\left(\mu \mathrm{g} \mathrm{mL}^{-1}\right)$ & 0.008 & 0.011 & 0.007 \\
\hline LOQ $\left(\mu \mathrm{g} \mathrm{mL}^{-1}\right)$ & 0.026 & 0.036 & 0.023 \\
\hline
\end{tabular}

Table 2. Precision (Intra day-Inter day).

\begin{tabular}{|c|c|c|c|c|c|c|c|c|}
\hline \multirow[b]{2}{*}{ S. No } & \multicolumn{4}{|c|}{ INTRA DAY } & \multicolumn{4}{|c|}{ INTER DAY } \\
\hline & $\begin{array}{c}\text { Amount of } \\
\text { phenothrin } \\
\text { taken } \\
\left(\mu \mathrm{g} \mathrm{mL}^{-1}\right)\end{array}$ & $\begin{array}{c}\text { Amount of } \\
\text { phenothrin } \\
\text { found } \\
\left(\mu \mathrm{g} \mathrm{mL} \mathbf{L}^{-1}\right)\end{array}$ & Mean & SD & $\begin{array}{c}\text { Amount of } \\
\text { phenothrin } \\
\text { taken } \\
\left(\mu \mathrm{g} \mathrm{mL} \mathbf{~ m}^{-1}\right)\end{array}$ & $\begin{array}{c}\text { Amount of } \\
\text { phenothrin } \\
\text { found } \\
\left(\mu \mathrm{g} \mathrm{mL}^{-1}\right)\end{array}$ & Mean & SD \\
\hline \multirow{3}{*}{1} & \multirow{3}{*}{3.00} & 3.21 & \multirow{3}{*}{3.11} & \multirow{3}{*}{0.12} & \multirow{3}{*}{3.00} & 3.21 & \multirow{3}{*}{2.99} & \multirow{3}{*}{0.20} \\
\hline & & 3.15 & & & & 2.90 & & \\
\hline & & 2.98 & & & & 2.85 & & \\
\hline \multirow{3}{*}{2} & \multirow{3}{*}{5.00} & 5.05 & \multirow{3}{*}{5.06} & \multirow{3}{*}{0.12} & \multirow{3}{*}{5.00} & 4.91 & \multirow{3}{*}{4.99} & \multirow{3}{*}{0.11} \\
\hline & & 4.95 & & & & 4.95 & & \\
\hline & & 5.18 & & & & 5.11 & & \\
\hline
\end{tabular}




\begin{tabular}{|c|c|c|c|c|c|c|c|c|}
\hline \multirow[t]{3}{*}{3} & \multirow[t]{3}{*}{7.00} & 7.11 & \multirow{3}{*}{6.99} & \multirow{3}{*}{0.11} & \multirow{3}{*}{7.00} & 6.95 & \multirow{3}{*}{6.98} & \multirow{3}{*}{0.10} \\
\hline & & 6.95 & & & & 6.90 & & \\
\hline & & 6.90 & & & & 7.08 & & \\
\hline & & & & & & & & \\
\hline & $\begin{array}{c}\text { Amount of } \\
\text { penconazole } \\
\text { taken } \\
\left(\mu \mathrm{g} \mathrm{mL}^{-1}\right)\end{array}$ & $\begin{array}{c}\text { Amount of } \\
\text { penconazole } \\
\text { found } \\
\left(\mu \mathrm{g} \mathrm{mL} \mathbf{L}^{-1}\right)\end{array}$ & Mean & SD & $\begin{array}{c}\text { Amount of } \\
\text { penconazole } \\
\text { taken } \\
\left(\mu \mathrm{g} \mathrm{mL} \mathbf{L}^{-1}\right)\end{array}$ & $\begin{array}{c}\text { Amount of } \\
\text { penconazole } \\
\text { found } \\
\left(\mu \mathrm{g} \mathrm{mL} \mathbf{L}^{-1}\right)\end{array}$ & Mean & SD \\
\hline 1 & 0.50 & 0.53 & & & & 0.48 & & \\
\hline & & 0.51 & 0.51 & 0.02 & 0.50 & 0.46 & 0.48 & 0.03 \\
\hline & & 0.50 & & & & 0.51 & & \\
\hline 2 & 0.75 & 0.73 & & & & 0.69 & & \\
\hline & & 0.69 & 0.72 & 0.03 & 0.75 & 0.71 & 0.68 & 0.03 \\
\hline & & 0.75 & & & & 0.65 & & \\
\hline 3 & 1.00 & 1.05 & & & & 0.98 & & \\
\hline & & 0.98 & 1.05 & 0.07 & 1.00 & 0.95 & 0.96 & 0.02 \\
\hline & & 1.11 & & & & 0.96 & & \\
\hline & & & & & & & & \\
\hline & $\begin{array}{c}\text { Amount of } \\
\text { promecarb } \\
\text { taken } \\
\left(\mu \mathrm{g} \mathrm{mL} \mathbf{~}^{-1}\right)\end{array}$ & $\begin{array}{c}\text { Amount of } \\
\text { promecarb } \\
\text { found } \\
\left(\mu \mathrm{g} \mathrm{mL} \mathbf{L}^{-1}\right)\end{array}$ & Mean & SD & $\begin{array}{c}\text { Amount of } \\
\text { promecarb } \\
\text { taken } \\
\left(\mu \mathrm{g} \mathrm{mL} \mathbf{~ m}^{-1}\right)\end{array}$ & $\begin{array}{c}\text { Amount of } \\
\text { promecarb } \\
\text { found } \\
\left(\mu \mathrm{g} \mathrm{mL} \mathbf{L}^{-1}\right)\end{array}$ & Mean & SD \\
\hline 1 & 0.50 & 0.51 & & & & 0.48 & & \\
\hline & & 0.53 & 0.51 & 0.02 & 0.50 & 0.46 & 0.47 & 0.01 \\
\hline & & 0.49 & & & & 0.46 & & \\
\hline & & 1.10 & & & & 0.98 & & \\
\hline 2 & 1.00 & 1.00 & 1.05 & 0.05 & 1.00 & 0.95 & 0.97 & 0.02 \\
\hline & & 1.05 & & & & 0.97 & & \\
\hline & & 1.48 & & & & 1.45 & & \\
\hline 3 & 1.50 & 1.50 & 1.50 & 0.02 & 1.50 & 1.48 & 1.48 & 0.03 \\
\hline & & 1.52 & & & & 1.51 & & \\
\hline
\end{tabular}

Accuracy: The accuracy of the tested analytical method is the closeness of the measured value to the true value for the sample. In our study, the pesticide residue was added to the sample without pesticide residues. In the work-up, dichloromethane, ethyl acetate and hexane were tested as extraction solutions. Recovery values for this study are given in the Table 3.

Table 3. Recovery percentage values for solvent selection.

\begin{tabular}{|c|c|c|c|}
\hline Compounds & $\begin{array}{c}\text { \% Recovery } \\
\text { (dichoromethane) }\end{array}$ & \% Recovery (ethyl acetate) & \% Recovery (n-hexane) \\
\hline Phenothrin & $89-91$ & $80-83$ & $30-33$ \\
\hline Penconazole & $96-98$ & $72-75$ & $60-62$ \\
\hline Promecarb & $85-90$ & $68-73$ & $63-68$ \\
\hline
\end{tabular}

The best values were obtained with dichloromethane. Accuracy studies were carried out with dichloromethane. Accuracy was usually expressed as the standard deviation or percentage relative error and mean $\%$ recovery of analytical method (Table 4 ).

Table 4. Accuracy/Recovery studies.

\begin{tabular}{|c|c|c|c|c|c|}
\hline S. No & $\begin{array}{c}\text { Amount of } \\
\text { phenothrin } \\
\text { added in } \\
\left(\mu g \mathrm{~mL}^{-1}\right) \\
\text { injection }\end{array}$ & $\begin{array}{c}\text { Amount of } \\
\text { phenothrin } \\
\text { found } \\
\left(\mu \mathrm{g} \mathrm{mL} \mathbf{L}^{-1}\right)\end{array}$ & \% Recovery & $\begin{array}{c}\text { Avarage } \\
\text { recovery in \% }\end{array}$ & SD \\
\hline \multirow{2}{*}{1} & \multirow{2}{*}{4.00} & 3.50 & 87.50 & \multirow{2}{*}{89.17} & \multirow{2}{*}{1.91} \\
\hline & & 3.65 & 91.25 & & \\
\hline
\end{tabular}




\begin{tabular}{|c|c|c|c|c|c|}
\hline & & 3.55 & 88.75 & & \\
\hline \multirow{3}{*}{2} & \multirow{3}{*}{6.00} & 5.5 & 91.67 & \multirow{3}{*}{91.00} & \multirow{3}{*}{0.60} \\
\hline & & 5.45 & 90.83 & & \\
\hline & & 5.43 & 90.50 & & \\
\hline \multirow{3}{*}{3} & \multirow{3}{*}{8.00} & 7.25 & 90.63 & \multirow{3}{*}{90.83} & \multirow{3}{*}{0.95} \\
\hline & & 7.35 & 91.88 & & \\
\hline & & 7.2 & 90.00 & & \\
\hline & & & & & \\
\hline & $\begin{array}{c}\text { Amount of } \\
\text { penconazole } \\
\text { added in } \\
\left(\mu \mathrm{mL}^{-1}\right) \\
\text { injection }\end{array}$ & $\begin{array}{c}\text { Amount of } \\
\text { penconazole } \\
\text { found } \\
\left(\mu \mathrm{g} \mathrm{mL}^{-1}\right)\end{array}$ & \% Recovery & $\begin{array}{c}\text { Avarage } \\
\text { recovery in \% }\end{array}$ & SD \\
\hline \multirow{3}{*}{1} & \multirow{3}{*}{0.40} & 0.38 & 95.00 & \multirow{3}{*}{97.50} & \multirow{3}{*}{2.50} \\
\hline & & 0.39 & 97.50 & & \\
\hline & & 0.40 & 100.00 & & \\
\hline \multirow{3}{*}{2} & \multirow{3}{*}{0.60} & 0.60 & 100.00 & \multirow{3}{*}{96.11} & \multirow{3}{*}{4.19} \\
\hline & & 0.58 & 96.67 & & \\
\hline & & 0.55 & 91.67 & & \\
\hline \multirow{3}{*}{3} & \multirow{3}{*}{0.80} & 0.78 & 97.50 & \multirow{3}{*}{97.92} & \multirow{3}{*}{0.72} \\
\hline & & 0.79 & 98.75 & & \\
\hline & & 0.78 & 97.50 & & \\
\hline & & & & & \\
\hline & $\begin{array}{l}\text { Amount of } \\
\text { promecarb } \\
\text { added in } \\
\left(\mu g \mathrm{~mL}^{-1}\right) \\
\text { injection }\end{array}$ & $\begin{array}{c}\text { Amount of } \\
\text { promecarb } \\
\text { found } \\
\left(\mu \mathrm{g} \mathrm{mL} \mathbf{L}^{-1}\right)\end{array}$ & $\%$ recovery & $\begin{array}{c}\text { Avarage } \\
\text { recovery in \% }\end{array}$ & SD \\
\hline \multirow{3}{*}{1} & \multirow{3}{*}{0.75} & 0.63 & 84.00 & \multirow{3}{*}{85.33} & \multirow{3}{*}{1.33} \\
\hline & & 0.65 & 86.67 & & \\
\hline & & 0.64 & 85.33 & & \\
\hline \multirow{3}{*}{2} & \multirow{3}{*}{1.00} & 0.87 & 87.00 & \multirow{3}{*}{86.67} & \multirow{3}{*}{1.53} \\
\hline & & 0.88 & 88.00 & & \\
\hline & & 0.85 & 85.00 & & \\
\hline \multirow{3}{*}{3} & \multirow{3}{*}{1.25} & 1.11 & 88.80 & \multirow{3}{*}{90.13} & \multirow{3}{*}{3.03} \\
\hline & & 1.10 & 88.00 & & \\
\hline & & 1.17 & 93.60 & & \\
\hline
\end{tabular}

The recoveries obtained for penconazole were similar or higher to other studies which used different extraction methods $[9,11]$. In different studies, recovery studies for penconazole were made from different samples. The values in the studies have varied from sample to sample. $[12,13]$. The recovery value for promecarb is slightly lower than the literature. this is the sample medium for the reason [14].

Limit of Detection (LOD) and Limit of Quantitation (LOQ): The LOD and LOQ values for the study were given in the Table 1 . The LOD 2-10 $\mu \mathrm{g} \mathrm{kg}$-1 for penconazole were reported $[10,11,15,16]$. The LOD values given in different studies for promecarb are between 0.70 and $2.14 \mu \mathrm{g} \mathrm{kg}^{-1}[17,18]$. The LOD value phenothrin $5 \mu \mathrm{g} \mathrm{kg}^{-1}$ was reported $[19,20]$.

\subsection{Real Sample}

Ten samples were taken from different tobacco shops. This sample was prepared in the sample preparation phase. Dichloromethane is preferred as extraction solvent. In the samples, none of the pesticides studied were detected.

\section{Conclusion}

The method described facilitates the quantitative and qualitative residue determination of penconazole, promecarb and phenothrin for analysis in tobacco. Dichloromethane was used for extraction of three pesticides. The detection limit values were below 0.060

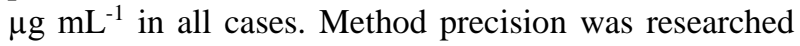
and SDs (intra- and inter-day) were good. Pesticides studied were not detected in tobacco samples. The reason for this is that pesticides in the study were not applied to tobacco imported into the shops. Or the 
pesticides are deteriorated for too long periods of time. Tobacco is a sample plant. Similar studies can be done in different samples (plant, food, etc.).

\section{References}

1. Melgar, M.J, Santaeufemia, M, Garcìa, M.A, Organophosphoru pesticide residues in raw milk and infant formulas from Spanish northwest, Journal of Environmental Science and Health, Part B, $2010,45,595-600$

2. Ergonen, A.T, Salacin S, Ozdemir M.H, Pesticide use among greenhouse workers in Turkey. The Journal of Clinical Forensic Medicine, 2005, 12, 205-208.

3. Blair, A, Zahm, S.H, Pearce, N.E, Heineman E.F, Fraumeni J, Clues to cancer etiology from studies of farmers, Scandinavian Journal of Work, Environment and Health, 1992, $18,209-215$.

4. Nicolopoulou-Stamati, P, Maipas, S, Kotampasi, C, Stamatis, P, Hens, L, Chemical Pesticides and Human Health: The Urgent Need for a New Concept in Agriculture, Frontiers Public Health, 2016, 4(148), 1-8.

5. Sun, X.H, Song, J.R., Tan, Z.C, Di, Y.Y, Ma, H.X, Wang, M.H, Sun, L.X, Heat capacity and enthalpy of fusion of penconazole, Thermochimica Acta, 413(1-2), 261-265.

6. Jimenez, J.J, Bernal, J.L, del Nozal, M.J, Toribio, L, Arias, E, Analysis of pesticide residues in wine by solid-phase extraction and gas chromatography with electron capture and nitrogenphosphorus detection, Journal of Chromatography A, 2001, 919, $147-156$.

7. Gelsomino, A, Petrovičowȧ, B, Tiburtini, S, Magnani, E, Felici, $\mathrm{M}$, Multiresidue analysis of pesticides in fruits and vegetables by gel permeation chromatography followed by gas chromatography with electron-capture and mass spectrometric detection, Journal of Chromatography A, 1997, 782, 105-122.

8. Oliva, J, Navarro, S, Barba, A, Navarro G, Determination of chlorpyrifos, penconazole, fenarimol, vinclozolin and metalaxyl in grapes, must and wine by on-line microextraction and gas chromatography, Journal of Chromatography A, 1999, 833, 4351.

9. Navarro, S, Barba, A, Navarro, G, Vela, N, Oliva, J, Multiresidue method for the rapid determination - in grape, must and wine-of fungicides frequently used on vineyards, Journal of Chromatography A, 2000, 882, 221-229.
10. Arrebola, F.J, Martínez Vidal, J.L, Mateu-Sánchez, M, ÁlvarezCastellón, F.J, Determination of 81 multiclass pesticides in fresh foodstuffs by a single injection analysis using gas chromatography-chemical ionization and electron ionization tandem mass spectrometry, Analytica Chimica Acta, 2003, 484, $167-180$

11. Pan, H.J, Ho, W.H, Determination of fungicides in water using liquid phase microextraction and gas chromatography with electron capture detection, Analytica Chimica Acta, 2004, 527, $61-67$.

12. Hirahara, Y, Tsumura, Y, Nakamura, Y, Tonogai, Y, Shibata, T, Analysis of Phenothrin and Its Metabolite 3-Phenoxybenzoic Acid (PBA) in Agricultural Products by GC and lon-Trap GC/MS, Journal of Food Protection, 1997, 60(3), 305-309.

13. Sakaue, S, Kitajima, M, Doi, T, High Performance Liquid Chromatographic Determination of d-Phenothrin (Sumithrin $\left({ }^{\circledR}\right)$ in Shampoo, Agricultural and Biological Chemistry, 1985, 49(9), 2787-2789.

14. Pacioni, N.L, Veglia, A.V, Determination of poorly fluorescent carbamate pesticides in water, bendiocarb and promecarb, using cyclodextrin nanocavities and related media, Analytica Chimica Acta, 2007, 583, 63-71

15. Sicbaldi, F, Sarra, A, Copeta, G.L, Diatomaceous earth-assisted extraction for the multiresidue determination of pesticides, Journal of Chromatography A, 1997, 765, 23-30.

16. Millän, S, Sampedro, M.C, Unceta, N, Goicolea, M.A Rodriguez, E, Barrio, R.J, Coupling solid-phase microextraction and high-performance liquid chromatography for direct and sensitive determination of halogenated fungicides in wine, Journal of Chromatography A, 2003, 995, 135-142.

17. Ferrer, I, Thurman, E.M, Liquid chromatography time-of-flight mass spectrometry:principles, tools, and application for accurate mass analysis, John Wiley \& Sons, Inc, 2009, 280 p., pp. 251.

18. Pang, G.F, Analytical Methods for Food Safety by Mass Spectrometry: Volume I Pesticides, Academic Press, 2018, 880 p., pp. 43.

19. Lunn, G, HPLC Methods for Recently Approved Pharmaceuticals, John Wiley \& Sons, Inc., 2005, pp. 26.

20. Loper, B.L, Anderson, K.A, Determination of pyrethrin and pyrethroid pesticides in urine and water matrixes by liquid chromatography with diode array detection, Journal of AOAC International, 2003, 86(6), 1236-1240. 